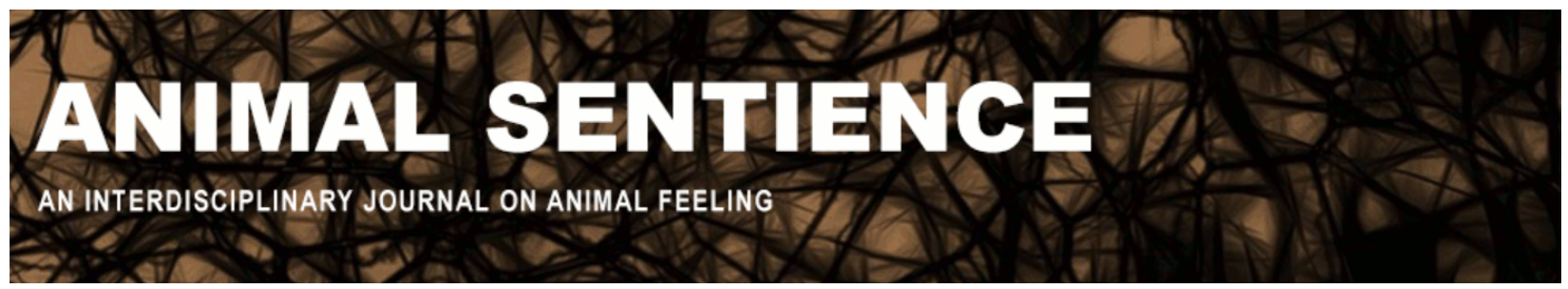

Franks, Becca; Sebo, Jeff; and Horowitz, Alexandra (2018) Fish are smart and feel pain: What about joy?. Animal Sentience 21(16)

DOI: $10.51291 / 2377-7478.1368$

Date of submission: 2018-09-06

Date of acceptance: 2018-09-14 (c) 


\title{
Fish are smart and feel pain: What about joy?
}

Commentary on Sneddon et al. on Sentience Denial

\author{
Becca Franks ${ }^{1}$, Jeff Sebo ${ }^{1}$ \& Alexandra Horowitz ${ }^{2}$ \\ ${ }^{1}$ Department of Environmental Studies, New York University \\ ${ }^{2}$ Department of Psychology, Barnard College
}

\begin{abstract}
Sneddon et al. rightly point out that the evidence of fish pain is now so strong and comprehensive that arguments against it have become increasingly difficult to defend in balanced academic discourse. But sentience involves more than just pain. Recent research indicates that fish have an impressive range of cognitive capacities, including the capacity for pleasure, in the form of play and other behaviors likely to involve positively valenced experience. Having made the case for pain, research can now focus on other aspects of fish sentience. Doing so will not only provide a more complete picture of the mental lives and abilities of fish, but it will also promote their welfare and protection.
\end{abstract}

Becca Franks is a visiting assistant professor in the Department of Environmental Studies at New York University. She studies well-being and motivation, with a focus on aquatic animal welfare. Website

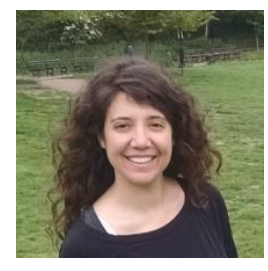

Jeff Sebo is clinical assistant professor of Environmental Studies; affiliated professor of Bioethics, Medical Ethics, and Philosophy; and director of the Animal Studies M.A. Program at New York University. He studies bioethics, animal ethics, and environmental ethics. Website

Alexandra Horowitz is adjunct associate professor of Psychology and English and head of the Dog Cognition Lab at Barnard College. She studies the perceptual experience of dogs as well as aspects of the human-dog relationships. Website

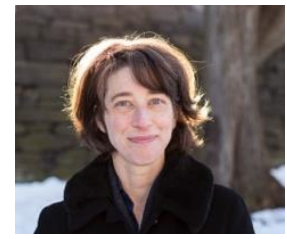

Sneddon et al. (2018) write that "more funding is needed in the area of fish welfare to provide robust empirical evidence we can use to inform the humane and ethical treatment of fish." We ask: What sort of additional empirical evidence is required? 
Thus far, the debate over fish sentience has focused almost entirely on whether fish can feel pain (e.g., Key, 2016). Pain is a complicated concept that cannot be proven or disproven in a species through a single, stand-alone experiment (Sneddon, Elwood, Adamo, \& Leach, 2014). The body of evidence as a whole provides strong reason to accept that fish have experiences that we can plausibly describe as pain: Fish pay to avoid potentially painful stimuli, forfeit good outcomes for the sake of avoiding such stimuli, and seek out analgesics after potentially painful procedures (Sneddon, 2015). These behaviors require active decision making and are thus easier to explain by accepting that fish can experience pain rather than assuming that they cannot.

Pain, however, is not the sum-total of sentience. Sentience is a complicated concept, but most scholars agree that it involves the ability to experience pain and pleasure (Broom, 2016; Harnad, 2016). While scientific studies over the past several years have indicated that fish have the cognitive equipment necessary for rich mental lives (Brown, 2015), the scientific study of fish pleasure has been relatively neglected. Thus, focusing future research on fish pleasure is likely to generate a wealth of theoretically and practically useful information, including answers to questions about what kinds of positive experiences fish may have and under what circumstances they might have them.

Several decades ago, the positive psychology movement sought to correct a similar bias in the human literature, arguing that beyond being a luxury, positive psychology is at the very core of human experience (Seligman \& Csikszentmihalyi, 2000). More recently, the field of animal welfare also began to consider ways to promote positive welfare beyond simply trying to alleviate poor welfare (Boissy et al., 2007; Mellor, 2014; Yeates \& Main, 2008). Even though fish have yet to benefit directly from these correctives, both fields - positive psychology and animal welfare - contain insights about ways forward for research on fish pleasure.

In positive psychology, Fredrickson (2013) has identified ten core positive emotions: joy, gratitude, serenity, interest, hope, pride, amusement, inspiration, awe, and love. While these might seem like strange words to apply to a fish (at least from a behaviorist perspective), the field of animal welfare is beginning to develop methodologies for identifying similar experiences in nonhuman animals. For example, studies on cognitive biases in nonhuman animals suggest that animals with better welfare have more optimistic interpretations of ambiguous cues (Baciadonna \& McElligott, 2015; Harding, Paul, \& Mendl, 2004). In other words, they are hopeful. In addition, behavioral research with many species has provided evidence of curiosity (e.g., Berlyne, 1966; Glickman \& Sroges, 1966; Hall, Melfi, Burns, McGill, \& Doyle, 2018), which is defined as the motivation to gain information. In other words, they display interest.

The existing literature on fish pleasure is slim, but promising. Studies dating back to the early twentieth century have examined spontaneous leaping and somersaulting behavior in fish, as well as voluntary and nonfunctional object manipulation and social interaction that fulfill the criteria of play (Burghardt, 2005; Fagen, 2017). As a naturally occurring behavior, play may provide the best example of a behavior that is widely observed across the animal kingdom (Ahloy-Dallaire, Espinosa, \& Mason, 2017). And, in humans at least, play is associated with intensely positive emotional experiences like joy and amusement. Studies of participation in play may be the most fruitful way to develop theoretical and empirical markers of positive emotional experiences in nonhuman animals, including fish. 
Other promising lines of research include preferential attachment (aka friendships) in guppies (Heathcote, Darden, Franks, Ramnarine, \& Croft, 2017), social motivation in cichlids (Galhardo, Almeida, \& Oliveira, 2011), and free-choice exploration in zebrafish (Graham, von Keyserlingk, \& Franks, 2018). Most recently, research with zebrafish suggests that when they are housed in naturalistic environments, they engage in heightened shoaling behavior - protracted bouts of tight group cohesion and increased behavioral synchrony - another behavior that may yield insights for future work on positive emotion in fish (Franks, Graham, \& von Keyserlingk, 2018). Further developing operational definitions of positive emotions such as joy, gratitude, and serenity will allow us to test whether such terms should continue to be reserved to a single species (i.e., ourselves).

The human impact on fish is increasing at an alarming rate: Aquaculture and the use of fish in science is expanding rapidly, as are habitat degradation and threats to wild populations from overfishing. The pressures to understand fish sentience are more urgent than ever, yet both academics and the general public remain focused primarily on pain, where the evidence is already compelling. We need a more complete picture of fish sentience. To ground decisionmaking about humane and ethical treatment, the biggest need going forward is for research on positive emotional experience in fish, including joy.

\section{References}

Ahloy-Dallaire, J., Espinosa, J., \& Mason, G. (2017). Play and optimal welfare: Does play indicate the presence of positive affective states? Behavioural Processes.

Baciadonna, L., \& McElligott, A. (2015). The use of judgement bias to assess welfare in farm livestock. Animal Welfare, 24(1), 81-91.

Berlyne, D. E. (1966). Curiosity and exploration. Science, 153(3731), 25-33.

Boissy, A., Manteuffel, G., Jensen, M. B., Moe, R. O., Spruijt, B., Keeling, L. J., Winckler, C., Forkman, B., Dimitrovi, I., Langbein, J., Bakken, M., Veissier, I., \& Aubert, A. (2007). Assessment of positive emotions in animals to improve their welfare. Physiology \& Behavior, 92(3), 375-397.

Broom, D. M. (2016). Sentience and animal welfare: New thoughts and controversies. Animal Sentience 5(11).

Brown, C. (2015). Fish intelligence, sentience and ethics. Animal Cognition, 1-17.

Burghardt, G. M. (2005). The origins of vertebrate play: Fish that leap, juggle, and tease. In The Genesis of Animal Play: Testing the Limits (p. 501). Cambridge, MA: MIT Press.

Fagen, R. (2017). Salmonid jumping and playing: Potential cultural and welfare implications. Animals, 7(6), 42.

Franks, B., Graham, C., \& von Keyserlingk, M. (2018). Is heightened-shoaling a good candidate for positive emotional behavior in zebrafish? Animals, 8(9), 152.

Fredrickson, B. L. (2013). Positive emotions broaden and build. In P. Devine \& A. Plant (Eds.), Advances in experimental social psychology (Vol. 47, pp. 1-54). San Diego, CA: Academic Press.

Galhardo, L., Almeida, O., \& Oliveira, R. F. (2011). Measuring motivation in a cichlid fish: An 
adaptation of the push-door paradigm. Applied Animal Behaviour Science, 130(1-2), 60-70. Graham, C., von Keyserlingk, M. A. G., \& Franks, B. (2018). Free-choice exploration increases affiliative behaviour in zebrafish. Applied Animal Behaviour Science, 203, 103-110.

Hall, B. A., Melfi, V., Burns, A., McGill, D. M., \& Doyle, R. E. (2018). Curious creatures: A multitaxa investigation of responses to novelty in a zoo environment. PeerJ, 6, e4454.

Harding, E. J., Paul, E. S., \& Mendl, M. T. (2004). Animal behaviour: Cognitive bias and affective state. Nature, 427(6972), 312.

Harnad, S. (2016). Animal sentience: The other-minds problem. Animal Sentience 1(1).

Heathcote, R. J. P., Darden, S. K., Franks, D. W., Ramnarine, I. W., \& Croft, D. P. (2017). Fear of predation drives stable and differentiated social relationships in guppies. Scientific Reports, 7, 41679.

Key, B. (2016). Why fish do not feel pain. Animal Sentience 3(1).

Mellor, D. J. (2014). Positive animal welfare states and encouraging environment-focused and animal-to-animal interactive behaviours. New Zealand Veterinary Journal, 63(1), 9-16.

Seligman, M. E. P., \& Csikszentmihalyi, M. (2000). Positive psychology - An introduction. American Psychologist, 55(1), 5-14.

Sneddon, L. U. (2015). Pain in aquatic animals. Journal of Experimental Biology, 218(7), 967-976.

Sneddon, L. U., Elwood, R. W., Adamo, S. A., \& Leach, M. C. (2014). Defining and assessing animal pain. Animal Behaviour, 97, 201-212.

Sneddon, L. U., Lopez-Luna, J., Wolfenden, D. C. C., Leach, M. C., Valentim, A. M., Steenbergen, P. J., Bardine, N., Currie, A. D., Broom, D. M., \& Brown, C. (2018). Fish sentience denial: Muddying the waters. Animal Sentience 21(1).

Yeates, J. W., \& Main, D. C. J. (2008). Assessment of positive welfare: A review. The Veterinary Journal, 175(3), 293-300. 